\title{
Mentalization And Personality Organization In Heroin Addicted Patients': A Narrative Analysis
}

\author{
Nikola Atanassov and Svetoslav Savov ${ }^{2}$ \\ New Bulgarian University
}

\begin{abstract}
The relationship between the dimensions of personality organization and the quality of mentalization is an important object of study in contemporary psychodynamic theory and it also contributes to the understanding of heroin addiction with comorbid personality disorders. The current study aims to assess levels of personality organization and its main domains (Identity, Object relations, Defense Mechanisms) in patients with opiate addiction, as well as the quality of affect mentalization and possible connections between them. In order to do so we have adopted quantitative text-analysis method of affect mentalization to parts of a interview, trying to show that the language which participants use could be in itself a psychodiagnostic means. A group of 30 heroin addicted patients in a methadone treatment programme and a control group of 30 healthy participants were assessed with the Structured Interview of Personality Organization (STIPO), VEA (Verbal Elaboration of Affect Scale) and The Measure of Affect Contents (MAC). Results show significant differences between the two groups, concerning all dimensions of personality organization as well as some core areas of affect mentalization. The capacity for affect mentalization is significantly correlated to the level of personality organization. The results are discussed from the point of view of the adopted theoretical models and the implications for psychotherapeutic work in the bio-psycho-social model.
\end{abstract}

\section{Introduction}

The onset of drug addiction is determined by a complex combination of constitutional, social and psychological factors. Psychodynamic thinking has from the very beginning associated addiction with experiences of early childhood trauma. It has been demonstrated that psychic trauma in childhood leads to a disturbance in the capabilities for mentalization and affect regulation. Mentalization theories see childhood trauma as a consequence of failure of the environment to provide the conditions necessary for the development of self and identity. Clinical data relate psychic trauma to the basic characteristics of the personality organization in patients with drug addiction, most often described as borderline (suffering from identity diffusion, partial object relations, predominance of primitive defense mechanisms), but extensive research is still lacking. In this paper, after a brief review of the some important trends in the development of the

${ }^{1}$ A shorter version of this paper with some of the results of the study is published in Atanassov, N. \& Savov, S. (in press). 'Psychic trauma and addiction'. In: Hamburger A. (ed.). Trauma, Trust and Memory: Social Trauma and Reconciliation in Psychoanalysis, Psychotherapy and Cultural Memory. London: Karnac Publishers.

2 Correspondence concerning this article should be addressed to Svetoslav Savov, Department of Cognitive Science and Psychology, New Bulgarian University, Sofia, Bulgaria, Motevideo Blvd. 21, 1608, room 401 - $1^{\text {st }}$ building, E-Mail: $\underline{\text { ssavov@nbu.bg }}$

Language and Psychoanalysis, 2016, 5 (1), 14-30

http://dx.doi.org/10.7565/landp.v5i1.1552 
psychodynamic conceptualizations of addictions, we present our study of the interconnections between the basic personality characteristics of heroin addicted patients and their mentalization capacities. Before presenting the empirical study we review a series of developments in the understanding of substance abuse starting with classical psychodynamic approaches based on drive/conflict models. Then, we present comprehensive theories of affect regulation which we see as a starting point for the transition to modern mentalization based conceptualizations. We describe the shift from the initial emphasis on instinctual gratification to the investigation of Ego development and pathology. We show how contemporary psychodynamic clinicians and researchers increasingly rely on mentalization based theories to explain personality pathology. We see the evolution of psychodynamic approaches to addictions as parallel to the general development in psychodynamic clinical theories.

\section{Classical Psychoanalytic Approaches to Addictions}

Many psychoanalytic pioneers were interested in the problem of substance abuse and addictions. Abraham (1926) tried to conceptualize this form of pathology from the point of view of libidinal theory, that is, as a symptom of regress to oral fixations and striving for 'orgasmic' experiences. Radó (1928) pointed out that not the toxic agent itself, but the impulse to use it, defines addictions. In general these authors understood substance abuse from the point of view of euphoric-pleasurable experiences, and believed that the symptom has a 'hidden' meaning (for example, symbolizing an orally gratifying object). Glover (1932), however, made an important breakthrough with his hypothesis that the psychoactive substance could be used 'progressively' - not only for regressive satisfaction, but also for protecting the subject from primitive (destructive and selfdestructive) impulses or even psychosis. Later on Fenichel (1945) underlined the deep seated depression and anxiety in addicts. These ideas would later serve as a basis for Khantizan's work on the 'Self-medication hypothesis'.

\section{Second generation models: Ego disturbances and affect regulation}

The next generation of psychodynamic models came largely from the ego-psychological tradition. The main difference between ego-psychological theories and classical drive/conflict models is that ego psychologists shifted the focus from the symptom to the personality deficits of addicts and their incapabilities for coping with traumatizing anxiety. Drug use was related to specific ego pathology manifested in quick shifts from depressive states to intensive arousal in conflictual relations with important others (Woody, 1977). Addicts react to situations of crisis with affect regression (totalization of feelings), which is dealt with by splitting unacceptable parts of internal or external reality and denying their existence. However, only when these series of operations are pharmacologically reinforced, a sense of mastery and raised self-esteem can be restored (Wurmser, 1977).

This generation of psychodynamically oriented clinicians concentrates on the clinical reality that patients with drug addiction complain of being either overwhelmed by intolerably painful affects or cut off from their emotions. Referring to these characteristics of the affective life of addicts, Wieder \& Kaplan (1969) define drugs as 'prosthesis' helping patients to regulate their impaired affective life. The primitive 
defense mechanisms drug addicts employ do not efficiently protect them from excessive anxious and depressive states. Consequently, addicts present not only interpersonal difficulties, affect storms and impulsive behavior, that are typical for patients with borderline personality disorder (Kernberg, 2003), but their whole emotional life is in a way much more easily 'somatized'. Thus, impaired affect regulation comes into focus as a central diagnostic feature of the disorder.

We can generalize that the contemporary psychodynamic approach to affective disorders in drug addicted patients abandoned altogether early conceptualization of pleasure seeking and symbolic importance of the drug. Instead, leading authors like Khantzian $(1980,2003)$ see the motivation behind substance use as an attempt for 'self-medication'. Patients addicted to opiates rely on the anti-aggressive effects of the substance which block disorganizing and threatening affective states of anger, pain, shame and loneliness. Drug addicts don't just search for an 'escape' or 'euphoria'. They actually need a shield that protects them from excess in anxiety. The lack of such protective system is a central characteristic of the borderline personality disorder as we will describe shortly.

Clinicians became naturally interested in the developmental origins of these affective disorders. Krystal (1974) points out that only when the small child is protected from exposure to continuous trauma in early relations, it can develop affect tolerance during latency and adolescence. He makes it clear that primary self-regulation deficits in drug addicts encompass a tendency for affective regress, deficient capability for using anxiety as a signal, as well as impaired tolerance for painful emotions, especially the primitive affect of undifferentiated anxiety-depression.

These deficiencies showing failure in the desomatization, verbalization and symbolization of affective experiences are quite often observable in psychosomatic conditions characterized by the state of 'alexythymia' (Sifneos, 1973). Addicted patients often share some of the basic components of alexythimic functioning (Taylor, Bagby \& Parker, 1997). Clinical experience shows that addicts also have severe difficulties in putting their mental states and affectivity into words. Without having a good enough understanding of them, these patients cannot modulate emotions and show tendencies for direct discharge of anxiety in behavior or somatizations. Interpersonal disappointments easily trigger rapid changes in mood, which an individual with certain predispositions would try to regulate by pharmacological means. Interestingly, alexythimia - a concept highly applicable to addictions, is also one of the roots of contemporary mentalizationbased theories, on which we will focus next.

\section{Contemporary mentalization-based understanding of addiction}

The concept of mentalization was introduced by Pierre Marty (1991) in the 70s as an extension of the research into psychosomatic phenomena (De Mijolla, 2005). Classically it refers to the quality and quantity of psychic representations, their verbalization and connections with affectivity. From another perspective - that of modern developmental psychopathology - Fonagy (2008, p. 4) defines mentalization as "a form of mostly preconscious imaginative mental activity, namely, interpreting human behavior in terms of intentional mental states (i.e., needs, desires, feelings, beliefs, goals, purposes, and reasons)". This conceptualization integrates the notion of 'theory of mind' in cognitive developmental models with attachment theory. It is based on three main assumptions (Weinberg 2006): 1) the feeling of the self as agent is rooted in the experience of being Language and Psychoanalysis, 2016, 5 (1), 14-30 
attributed psychic states by a significant other; 2) this capability is a function of the interaction between the caring figures through a process of mirroring; 3 ) its development can be impaired by traumatic experiences.

Attachment is seen as the main factor in the development of mentalization and the formation of internal representations of affective states. According to Bateman \& Fonagy (2004), patients with borderline personality disorder have difficulty in mentalizing mainly in interpersonal and intimate situations, where they are most vulnerable to excesses in anxiety. Deficits in mentalization prevent them from having a good enough 'buffer' from affects and trigger 'fight or flight' mechanisms. These observations seem highly relevant for the conceptualization of addictions, having in mind the high percent of co-morbidity with borderline personality disorder (Trull et al., 2000).

Allen, Fonagy \& Bateman (2008) describe a two-way interaction between substance abuse and mentalizing. Intoxication impairs mentalization of own emotional states as well as those of the attachment figures. Deficits in mentalization on the other hand contribute to an inclination for substance abuse under emotional stress caused by interpersonal conflicts with attachment figures.

Contrasting, but also complementing Fonagy's model, Bouchard and Lecours (2008) present a theory of mentalization focused on the development of thinking through binding of instinctual pressure in representative networks. These processes of psychic working through prevent direct discharge into actions or somatizations. Influenced by psychosomatic research done by Marty, Krystal's theory of emotions and Piaget's (1956) conceptualization of the child's intellectual development from sensor-motor activity towards formal verbal thought, Bouchard and Lecours understand affects as positively or negatively valenced psychological phenomena with a somato-motor tendency for action. This tendency is 'desomatized' by a complex process of psychic working through. They assume that representative deficits lead to an excess of the quantitative element (excitation), which has not been transformed into a psychic conflict. Forms of impulsivity, addicted behavior and somatization are understood from this point of view as an expression of accumulated drive impulses with no attributed psychological meaning.

The qualitative transformation of somatic, motoric and intersubjective excitations into mental contents can be seen on a continuum of increasing "mental" quality (Lecours \& Bouchard, 1997). Mentalization is seen as a "general class of mental operations, including representation and symbolization" ( $p$. 857) whereby representation is a formation of stable mental images, and symbolization is their linking and using them in an abstract manner as opposed to concrete dealing with experience.

Based on the work of Luquet, Marty and Bion the authors present a bi-dimensional model of the psychic elaboration (ibid). The first dimension encompasses four channels of expression of affect: somatic, motor, imagery and verbal expression. For each of these channels five degrees of containment can be considered: the disruptive impulsion (discharge of the overflow of excitation through uncontrolled direct expression), the modulated impulsion (affect is expressed but not reflected upon, although it has been minimally transformed by the preconscious); on the next three levels up - externalization, appropriation and meaning associations - affects are tolerated and contained, less intense and accessible for reflective activity. 
Bouchard and Lecours describe mentalization as the 'immune system' of the psyche, because it modifies external and internal pressures. Normally, mentalizing contributes to the coherent and meaningful experience of one's own psychic states. Instead of acquiring this tolerable distance from direct affective pressure drug addicts often suffer from severe anxiety and depression. These conditions are triggered by the deep conviction that the individual is helpless in regulating not only external reality but also his or her emotional states. Substance abuse is the copying mechanism which replaces mental processing of helplessness, apathy and emptiness, and thus brings back temporary control.

Since empirical research on personality organization and mentalization capacities in heroin addicted patients is scarce, in the present study we aim to find connections between levels and domains of personality organization according to Kernberg's structural model (1975) and the quality of affect mentalization.

\section{Narrative analysis in psychotherapy and psychoanalysis}

A long tradition in psychotherapy research is based on narrative analysis which is of no surprise since psychotherapy itself is a form of narrative research. The psychoanalytic therapist listens to the patient's discourse and finds meaning which is not obvious in the manifest language. This is possible because in the manifest content there are clues for the hidden meaning, or in other words, the conscious language includes information about the preconscious and unconscious languages, that is, contents outside the immediate awareness or repressed psychic material. One of the first attempts to connect linguistics with content analysis in clinical psychology is the study of pathological and normal language by Laffal (1965). Shortly after that Gottschalk \& Auerbach (1966) present their own method of content analysis of psychotherapy protocols. Luborsky \& Spence (1971) demonstrate the potential of computer technologies. Bucci et al. (1992) study verbal and non-verbal representations through computer analysis of referential activity. Hand in hand with that research tradition goes the use of semi-structured interviews. Shedler, Mayman \& Manis (1993) show that self-report instruments have limited validity since standard questionnaires tend to fail in differentiating mental health from the illusion of mental health created by defense mechanisms. Analysts are well aware that psychological distress is often expressed in a concealed way beneath the manifest content. Having all this in mind, we decided to adopt a methodology which combines the use of a semistructured interview and a comprehensive system for content analysis, which would allow us to explore the material in a deeper way. Although structured interviews show higher psychometric qualities compared to semi-structured or unstructured formats, we attempted to grasp the complexity and richness of the whole personality through this approach.

\section{Method}

\section{Design and Procedure of the Study}

We formed a clinical group of 30 heroin addicts treated in a methadone maintenance programme. They were recruited by the medical staff of the treatment facility and were given information that their participation is absolutely voluntary. All the participants were reimbursed with 10 euro for the efforts. Before the study each one of them was tested for drug intoxication and those with positive results were excluded from the study. 
We interviewed all the patients individually with the Structured Interview of Personality Organization 1.07 (STIPO) (Clarkin et al., 2006), after which we evaluated the transcribed narratives with the Verbal Elaboration of Affect Scale (VEA) (Lecours, 2013) and The Measure of Affect Contents (MAC) (Lecours, 2002). These instruments have never been used conjointly before.

The STIPO administration takes between 90 and 120 minutes, and the length of the narratives is between 14 and 20 pages (mean $=16$ pages). The interviews have been audio recorded and fully transcribed. For the goals of the narrative analysis with GEVA and MAC we used only the first three sections of the interview (Identity, Object Relations and Primitive defenses). The reason for this decision lies in the necessity to shorten the amount of material to be coded, but it is also theoretically guided - these are the three dimensions of personality that are critical for the structural diagnosis according to Kernberg's model.

The data were compared with the results of a control group of 30 healthy individuals, parallel in age, sex and education, and with no history of drug abuse. They were recruited with an advertisement in a social network and interviewed in the office of one of the researchers. The whole procedure has been approved by the Ethical committee of the Department of Cognitive Science and Psychology in New Bulgarian University, Sofia. Informed consent was obtained from all patients for participation in the study.

\section{Participants}

The mean age in the clinical group is 29.9 years ( $\mathrm{SD}= \pm 4.19$, range $22-38$ years). The majority $(70 \%)$ are between 26 and 34 years old. 15 participants $(50 \%)$ are female. 3 patients have $(10 \%)$ basic education, $23(76.67 \%)$ have high school education, and 4 $(13.33 \%)$ have university degree. $18(60 \%)$ work. The mean period of heroin abuse is 11.3 years $(\mathrm{SD}= \pm 4.01$, range $5-20$ years). The average dose of methadone is $139.83 \mathrm{ml}$ ( $\mathrm{SD}= \pm 77.75$, range $30-300 \mathrm{ml})$. The mean age in the control group is 29.3 years $(\mathrm{SD}=$ \pm 5.08 , range $20-44$ years). The majority $(60 \%)$ are between 26 and 34 years old. 15 participants are female. 3 participants $(10 \%)$ have basic education, $17(56.67 \%)$ have high school education and $9(30 \%)$ have university degree. $18(60 \%)$ work.

\section{Instruments}

\section{STIPO}

The Structured Interview of Personality Organization 1.07 is a manual for operationalized assessment of personality organization according to Kernberg's structural theory. It measures the following dimensions: Identity, Quality of Object relations, Primitive defenses, Coping and rigidity, Aggression and Moral values. The STIPO explores both the patient's behavioral world and inner world, and it is scored by the interviewer while it is administered: Each item is rated on a 0-2 scale, with zero reflecting the absence of pathology, two reflecting the clear presence of pathology, and one representing an intermediate status. In addition, the interviewer also completes a 5-point rating for each domain, which defines the range of health and pathology for each section being rated. The instrument has been translated into Bulgarian by two clinical psychologists and their translations have been compared in order to reach an optimal final version. A back- 
translation did not take place due to minor differences in the compared translations and good response from study participants in three exploratory interviews. The use of the instrument has been periodically consulted with the authors either 'live' or through email. The available data show that STIPO offers a reliable and valid assessment of the organization of personality (Hörz et al., 2011; Stern et al., 2010).

\section{VEA}

Verbal Elaboration of Affect Scale (VEA) is an observer-rated instrument that brings the content analysis tradition into psychodynamic theory. The scale is based on Bouchard and Lecours' (2008) theory of mentalization, and measures verbal elaboration of affect by segmentation and coding of narratives. It consists of two orthogonal dimensions: 1) four channels of affect expression: somatization, motor activity, imagery and verbalization, and 2) five levels ot affect tolerance and abstraction: disruptive impulsion, modulated impulsion, externalization, appropriation (subjectivation) and meaning connection. These are 20 possible forms ( 4 channels x 5 levels) in which a given affect expression could fit in. They are used for calculating a weighted score for the quality of affect mentalization. The scale can be used on verbal material with a free enough expression of affect. The method is based on coding the narrative by trained experts. The different channels are coded as follows: verbal - ' $v$ ', imagery - 'i', motor - 'm', and somatic - 's'.

The scale has been shown to provide reliable and valid assessment of affect mentalization in individual patients or whole clinical groups (Lecours et al., 2000; Lecours et al., 2007; Bouchard et al., 2008). The two experts in the present study have participated in a 5-days training with the author of the instrument.

\section{MAC}

The Measure of Affect Contents (MAC) is a companion instrument to VEA, allowing categorization of two affect groups: 1) basic, universal and inborn emotions (for example, joy), and 2) secondary emotions, which can be regarded as a combination of two or more basic emotions (for example, admiration for others, which can be viewed as a combination of joy, interest, love and wish). While GEVA assesses formal aspect of expression, MAC is focused on affect content. The total number of categories is 24 . In the present study we have focused on the following affect categories relevant for personality pathology: sadness, anger towards others, love towards others, fear, contempt towards others, as well as positive and negative affects in general (meaning all affect categories with negative valence).

\section{Results}

\section{Reliability}

The internal reliability in the present study is very good. We have calculated Cronbach's $\alpha$ for the 6 big scales of STIPO, and it ranges between .74 (Coping and rigidity) to .93 (Identity), while the total internal reliability for the 87 items is .97 . These results are comparable with the data from the German adaption of the instrument (Doering et al., 2013). 
Three raters took part in the assessment of the material. The inter-rater reliability of the STIPO was assessed by calculation of inter-class correlations of the 'clinical' (1-5) ratings, put by two independent raters who have either conducted the interview or listened to an audio recording. The correlations vary from .87 (Coping and rigidity) to .94 (Identity), and $100 \%$ for the assessment of the level of personality organization, which shows a very good inter-rater reliability. We calculated correlations between the two STIPO algorithms - clinical scales (1-5) and arithmetic scales (0-2), varying from $r=.70$ $(\mathrm{p}<.01)$ for the Object relations scale, to $\mathrm{r}=.87(\mathrm{p}<.01)$ for the Moral values scale. These are relatively lower scores compared to those demonstrated by Doering et al. (2013), and yet they show that the two algorithms could be used alternatively. In our study we used only the results from the STIPO arithmetic scales.

The inter-rater reliability of the narrative analysis has been calculated by the author of the instrument on the basis of 3 segmented and coded interviews before the actual start of the coding. These results are in the lower, yet acceptable spectrum. The percentage of agreement on the identification of affect units between the two experts and the author of the instrument is shown in kappa coefficients: .74 for expert 1 and .70 for expert 2. For the categories of MAC we calculated coefficients ranging from .83 to .60 , for the channels - .55 and .54; for the levels - .62 and .54; for the valence - .76 and .62. This means that the highest disagreement has been observed in the decision which channel to code (for example, verbal or imagery), and the lowest disagreement - in the affect categories of MAC and the valence of the affects (positive or negative). The differences in the coding procedures have been discussed so that a unified approach was applied in the actual assessment process.

\section{STIPO}

The data obtained from STIPO support previous research showing that patients with borderline personality disorder receive significantly lower results on all STIPO domains in comparison to a control group (Doering et al., 2013). Our study reached similar results for heroin addicted patients, who score lower on all dimensions in comparison to the clinical group (see Table 1 and Table $2^{3}$ ) - the highest difference has been observed in the Identity rating (mean: 1.10 in the clinical group and .37 in the control group, $p<.01$ ). The lowest difference is observed in the scale Coping and rigidity (mean: 38.53 in the control group in comparison to 22.47 in the clinical group, $p<.01$ ). Rentrop et al. (2014) have conducted a study dealing with the levels of personality organization based on the STIPO in a group of polydrug-using opiate-dependent patients. It fits well to the present work: $90 \%$ of the patients had at least one axis II disorder, and according to the STIPO, $100 \%$ of the patients were located at the level of borderline personality organization, indicating identity pathology according to Kernberg's model.

\footnotetext{
${ }^{3}$ The Identity scale of STIPO is the only normally distributed scale in the current study, so we used t-test for the statistical analysis. All the other scales were analyzed with the nonparametric Mann-Whitney U test. As previously noted, we used the 0-2 ratings for all the dimensions of personality organization (PO). The 1-5 rating was used only for the overall level of PO (normal, neurotic, borderline). 
Table 1

Differences in the STIPO scales between the two groups

\begin{tabular}{|c|c|c|c|}
\hline & Group & Mean & Significance (two-tailed) \\
\hline \multirow{2}{*}{$\begin{array}{l}\text { Personality } \\
\text { organization }\end{array}$} & Heroin addicts & 40.63 & \multirow{2}{*}{.00} \\
\hline & Control group & 20.37 & \\
\hline \multirow{2}{*}{$\begin{array}{c}\text { Object } \\
\text { relations }\end{array}$} & Heroin addicts & 42.42 & \multirow{2}{*}{.00} \\
\hline & Control group & 18.58 & \\
\hline \multirow{2}{*}{$\begin{array}{l}\text { Primitive } \\
\text { defenses }\end{array}$} & Heroin addicts & 41.65 & \multirow{2}{*}{.00} \\
\hline & Control group & 19.35 & \\
\hline \multirow{2}{*}{$\begin{array}{l}\text { Coping and } \\
\text { rigidity }\end{array}$} & Heroin addicts & 38.53 & \multirow{2}{*}{.00} \\
\hline & Control group & 22.47 & \\
\hline \multirow{2}{*}{ Aggression } & Heroin addicts & 45.05 & \multirow{2}{*}{.00} \\
\hline & Control group & 15.95 & \\
\hline \multirow{2}{*}{ Moral values } & Heroin addicts & 44.35 & \multirow{2}{*}{.00} \\
\hline & Control group & 16.65 & \\
\hline
\end{tabular}

Table 2

Differences in the Identity scale between the two groups

\begin{tabular}{|c|c|c|c|}
\hline Group & Mean & $\begin{array}{c}\text { Standard } \\
\text { deviation }\end{array}$ & $\begin{array}{c}\text { Standard } \\
\text { Error }\end{array}$ \\
\hline Heroin addicts & 1.10 & .26 & .05 \\
\hline Control group & .37 & .20 & .04 \\
\hline
\end{tabular}

\section{VEA}

The modalities and levels presented in the findings are based on the selected MAC categories. The results obtained from VEA show that the clinical group is characterized by a significantly higher use of lower mentalization levels: disruptive impulsion (mean: 34.47 in clinical group in comparison to 26.53 in the control group; $p<.01$ ) and modulated impulsion (.26 for the clinical group and .16 for the control group; $p<.01$ ), as well as lower use of externalization (.44 for the control group in comparison to .32 for the clinical group, $\mathrm{p}<.01)$. Another significant difference is the higher use of the motor channel in the clinical group $(.27$ against $.22, \mathrm{p}<.01)$ and a lower use of the somatic channel $(24.33$ against $36.67, \mathrm{p}<.01)$. Heroin addicted patients show significantly lower levels of mentalization of negative affects $(2.61$ against $2.37, \mathrm{p}<.01)$, and contempt ( 23.38 against 37.62 for the quality of mentalization, $p<.01$ ).

\section{Relationship between STIPO and VEA}

This whole section represents the relationship between the STIPO scales and the level of mentalization of the VEA scales. A significant negative correlation is found between the 
Identity scale and the quality of mentalization in the affect category contempt $(r=-.52, p$ $<.01)$, and a moderate one between Identity $(\mathrm{r}=-.49, \mathrm{p}<.01)$ and the overall assessment of verbal elaboration of affect $(\mathrm{r}=-.33 ; \mathrm{p}<.01)$. There is a significant negative correlation between the Aggression scale of STIPO and the categories contempt and negatively valenced affects $(\mathrm{r}=-.52$ and $\mathrm{r}=-.54 ; \mathrm{p}<.01)$. There is a moderate correlation between the Object relations scale and the quality of mentalization of contempt and negative affects categories $(\mathrm{r}=-.49$ and $\mathrm{r}=-.47, \mathrm{p}<.01)$. Primitive defenses is moderately correlated with contempt, negative affects and overall assessment of verbal elaboration of affect $(r=-.45, r=-.49$ and $r=-.32 ; p<.01)$. Probably the most important result is the moderate negative correlation between the Personality organization scale and the overall assessment of VEA $(r=-.34, p<.01)$, which shows that personality pathology is indeed related to deficits in affect mentalization.

We will now illustrate the results by showing how two patients approach a question from the STIPO. The question is: "Tell me about yourself, what are you like as a person?"

Patient 1: 'Hmm... I can think of stuff that upsets me (v4c-(cs)). I am not enough motivated to work, I am too kind (m4+(aa)) perhaps. I don't feel like doing anything meaningful in my life (v4-(de)). When I like a girl (v4+(aa)) and I put her above others (i4+(ada)), I experience difficulties talking to her."

Patient 2: 'I cannot describe myself. I am sick (s4-(ca)) of being hurt (v4gc-(t)). That's why I have become very aggressive $(\mathbf{m} 4 \mathbf{c}-(\mathbf{c a}))$. This aggression was not here before $(\mathbf{m} 4 \mathbf{g}+(\mathbf{c a}))$. If somebody says something to me, I respond: "Fuck you!" (v2-ca)). Then I take out the knife (m1-(ca)). And I will cut his head (m1-(ca)). I go crazy (i1-(ca))."

Obviously, these are small fragments from the interview and they are clearly insufficient to provide the basis for a complete assessment, but they can be useful for an illustration how we operate with the instruments.

From the point of view of STIPO, the first patient starts describing different problematic sides of his personality providing subjective experience. The second patient, however, shows a much more fragmented, action-oriented picture of himself, dominated by primitive aggression. There are 6 levels described in the STIPO: Normal, Neurotic 1 and 2, and Borderline 1, 2 and 3. According to Kernberg's model, the three critical dimensions for the assessment of the overall level of personality organization are Identity, Object relations and Primitive defenses. 
Table 3

Relationship between STIPO and VEA

\begin{tabular}{|c|c|c|c|c|c|c|c|c|c|}
\hline & & $\begin{array}{l}\text { Pos. } \\
\text { affects }\end{array}$ & Sadness & $\begin{array}{l}\text { Anger } \\
\text { s towards } \\
\text { others }\end{array}$ & Fear & $\begin{array}{l}\text { Contemp } \\
\text { towards } \\
\text { others }\end{array}$ & $\begin{array}{l}\text { Love } \\
\text { towards } \\
\text { others }\end{array}$ & $\begin{array}{l}\text { Neg. } \\
\text { affects }\end{array}$ & VEA \\
\hline Identity & $\begin{array}{l}\text { Spearman's } \\
\text { correlation } \\
\text { Significance } \\
\end{array}$ & $\begin{array}{l}.01 \\
.96\end{array}$ & $\begin{array}{l}-.27^{*} \\
.04\end{array}$ & $\begin{array}{l}.06 \\
.64\end{array}$ & $\begin{array}{l}-.11 \\
.38\end{array}$ & $\begin{array}{l}-.52^{* *} \\
.00\end{array}$ & $\begin{array}{l}-.14 \\
.29\end{array}$ & $\begin{array}{l}-.45^{* *} \\
.00\end{array}$ & $\begin{array}{l}-.33^{* *} \\
.01\end{array}$ \\
\hline $\begin{array}{l}\text { Object } \\
\text { relations }\end{array}$ & $\begin{array}{l}\text { Spearman's } \\
\text { correlation } \\
\text { Significance }\end{array}$ & $\begin{array}{l}.05 \\
.70\end{array}$ & $\begin{array}{l}-.18 \\
.16\end{array}$ & $\begin{array}{l}.08 \\
.56\end{array}$ & $\begin{array}{l}.01 \\
.93\end{array}$ & $\begin{array}{l}-.49^{* *} \\
.00\end{array}$ & $\begin{array}{l}-.03 \\
.83\end{array}$ & $\begin{array}{l}-.44^{* *} \\
.00\end{array}$ & $-.28^{*}$ \\
\hline $\begin{array}{l}\text { Primitive } \\
\text { defenses }\end{array}$ & $\begin{array}{l}\text { Spearman's } \\
\text { correlation } \\
\text { Significance }\end{array}$ & -.00 & $\begin{array}{l}-.13 \\
.32\end{array}$ & $\begin{array}{l}.07 \\
.58\end{array}$ & $\begin{array}{l}-.03 \\
.79\end{array}$ & $\begin{array}{l}-.45^{* *} \\
.00\end{array}$ & $\begin{array}{l}-.02 \\
.88\end{array}$ & $\begin{array}{l}-.49^{* *} \\
.00\end{array}$ & $\begin{array}{l}-.32^{*} \\
.01\end{array}$ \\
\hline $\begin{array}{l}\text { Coping } \\
\text { and rigidity }\end{array}$ & $\begin{array}{l}\text { Spearman's } \\
\text { correlation } \\
\text { Significance }\end{array}$ & .08 & $\begin{array}{l}.02 \\
.87\end{array}$ & $\begin{array}{l}.01 \\
.96\end{array}$ & $\begin{array}{l}.12 \\
.37\end{array}$ & $\begin{array}{l}-.27^{*} \\
.03\end{array}$ & $\begin{array}{l}.06 \\
.64\end{array}$ & $\begin{array}{l}-.33^{* *} \\
.01\end{array}$ & $\begin{array}{l}-.14 \\
.30\end{array}$ \\
\hline Aggression & $\begin{array}{l}\text { Spearman's } \\
\text { correlation } \\
\text { Significance }\end{array}$ & -.04 & $\begin{array}{l}-.27^{*} \\
.04\end{array}$ & $\begin{array}{l}-.01 \\
.95\end{array}$ & $\begin{array}{l}-.15 \\
.26\end{array}$ & $\begin{array}{l}-.52^{* *} \\
.00\end{array}$ & $\begin{array}{l}.03 \\
.81\end{array}$ & $\begin{array}{l}-.54^{* *} \\
.00\end{array}$ & $\begin{array}{l}-.37^{* *} \\
.00\end{array}$ \\
\hline $\begin{array}{l}\text { Moral } \\
\text { values }\end{array}$ & $\begin{array}{l}\text { Spearman's } \\
\text { correlation } \\
\text { Significance }\end{array}$ & .01 & $\begin{array}{l}-.24 \\
.06\end{array}$ & -.04 & $\begin{array}{l}-.04 \\
.78\end{array}$ & $\begin{array}{l}-.42^{* *} \\
.00\end{array}$ & $\begin{array}{l}.02 \\
.86\end{array}$ & $\begin{array}{l}-.44^{* *} \\
.00\end{array}$ & $\begin{array}{l}-.28^{*} \\
.03\end{array}$ \\
\hline $\begin{array}{l}\text { Personality } \\
\text { organization }\end{array}$ & $\begin{array}{l}\text { Spearman's } \\
\text { correlation } \\
\text { Significance }\end{array}$ & .07 & $\begin{array}{l}-.34^{* *} \\
.01\end{array}$ & .04 & $\begin{array}{l}-.11 \\
.41\end{array}$ & $\begin{array}{l}-.47^{* *} \\
.00\end{array}$ & $\begin{array}{l}-.09 \\
.49\end{array}$ & $\begin{array}{l}-.39^{* *} \\
.00\end{array}$ & $-.34^{* *}$ \\
\hline
\end{tabular}

** Significant correlation at level of significance $<.01$ (two-tailed).

\section{Table 4}

Relationship between Identity and the normally distributed scales of VEA

\begin{tabular}{|c|c|c|c|c|c|}
\hline & & Sadnes & $\begin{array}{c}\text { Love } \\
\text { towards } \\
\text { others } \\
\end{array}$ & $\begin{array}{c}\text { Negative } \\
\text { affects }\end{array}$ & $\begin{array}{c}\text { Verbal } \\
\text { elaboration } \\
\text { of affect }\end{array}$ \\
\hline Identity & $\begin{array}{l}\text { Pearson's } \\
\text { correlation } \\
\text { Significanc }\end{array}$ & $\begin{array}{l}-.28^{*} \\
.03\end{array}$ & $\begin{array}{l}-.10 \\
.45\end{array}$ & $\begin{array}{l}-.45^{* *} \\
.00\end{array}$ & $-.33^{*}$ \\
\hline
\end{tabular}

** Significant correlation at level of significance $<.01$ (two-tailed). 
The rest of the scales (Coping and rigidity, Aggression and Moral values) contribute to a more detailed and comprehensive assessment but are not crucial for it. So, each successive level of personality organization in that continuum reflects an increasing disturbance in the representations of self and others, the capacity to form and maintain close and fulfilling relations, and the flexible use of defense mechanisms.

If we go back to the clinical examples, the overall assessment with STIPO shows that patient 1 is a highly functioning borderline patient (or Borderline 1 in the STIPO classification). This means that he has a score 2 out of 5 for the clinical Identity scale (consolidated Identity, with some areas of slight deficit, e.g., superficiality or instability in sense of self and/or representations of others); score 3 out 5 for the Object relations scale (attachments are present, but increasingly superficial, brittle, and flawed; increasing tendency to view relationships in terms of need fulfillment; limited capacity for empathy with the other's needs independent of those of the subject); and score 3 out of 5 for the Primitive defenses scale (mixed pattern of endorsement of primitive defenses; shifts in perception of self and others are not pronounced, limited impairment in functioning due to use of primitive defenses).

Patient 2 functions at the lower borderline spectrum or Borderline 3 in the STIPO classification: 5 out of 5 for the Identity scale (severe identity pathology - highly contradictory, chaotically shifting views of self and others, inability to invest); 5 out of 5 for the Object relations scale (severe paucity of attachments; sees relationships entirely in terms of need fulfillment; no capacity for empathy; no capacity to sustain interest in others); and 5 out of 5 for the Primitive defenses scale (pervasive use of primitive defenses across situations; severe, radical shifts in perception of self and others to a degree that grossly interferes with functioning).

Then, if we look at the material using VEA, we see a major difference in the quality of affect mentalization. The first patient uses three channels of affect expression: verbal, imagery and motor. His affect representations are mainly on the $3^{\text {rd }}$ level. "Stuff that upsets me" ((v4c-(cs)) is level 4 reduced to level 3 because of externalization of the affect; "I like a girl" (v4+(aa)) is level 4. The second patient uses all channels (motor, verbal, imagery and somatic), but his language is behavior oriented (not describing subjective mental states) and is predominantly on the lower levels of affect expression (“... I will cut his head (m1-(ca)). I go crazy" (i1-(ca))). Correspondingly, the VEA score shows that patient 1 has higher mentalization capacities. Important additional information is that patient 1 started once per week psychodynamic psychotherapy and copes well in the addiction treatment programme (doesn't take drugs and has stable work) while the second patient dropped out of treatment.

\section{Discussion}

The overall results from the present study indicate several important trends. First, the clinical group shows disturbance in all personality dimensions which is an empirical validation of Kernberg's theory according to which borderline patients suffer from identity diffusion, impaired capacity for establishing and maintaining stable and fulfilling object relations, and predominant use of primitive defense mechanisms (i.e. splitting and projective identification). 
Second, heroin addicted patients mentalize their affectivity to a higher extend on lower mentalization levels of abstraction and tolerance of the affect in comparison to healthy individuals, and they use to a higher degree behavior-oriented representations. They show lower capacity for mentalization of negative affects, which corresponds to the findings of Walter et al. (2009) and Lecours \& Bouchard (2011) who state that the mentalization of negatively valenced affects is related to presence of personality pathology. Significantly lower results in the mentalization of contempt category shows once again difficulties in the verbalization of emotions in intimate interpersonal relationships. Perhaps in the lower levels of verbal elaboration of affect heroin patients face a dilemma - verbalizing affects through the somatic or through the motor channel - our results show that they choose predominantly the motor channel which can be understood in the context of the sample. These are patients in a methadone assisted maintenance program who no longer suffer from the typical abstinence syndrome, as they experience a constant anti-anxiety and anti-depressive affect from the substance. This means that they most probably get oriented towards external reality, hence the use of behavioral representations.

Finally, our results show that the personality dimensions defining the differential assessment of the personality organization (Identity, Object relations and Primitive defenses) are indeed related to the quality of affect mentalization. The overall level of personality organization is significantly related to the quality of verbal elaboration of affect and also the mentalization of depressive affects, which is expected since borderline patients typically experience difficulties in working through losses and separations. These results support the findings of Fischer-Kern et al. (2010) who state that personality organization is related to the quality of reflective functioning.

To summarize, the language of heroin addicted patients is dominated by chronic negative affectivity and not well articulated intolerance for mutual dependency (that is, low mentalization of the 'contempt towards' other category). The quality of affect representations can be used to assess both reflective functioning and personality organization, possibly also prognosis of treatment response. Action-oriented words and difficulties in 'owning' emotions (that is, evacuating or externalizing them) stand for lower mentalization capacities and hence more severe personality pathology and worse prognosis. It is worth noting that it is not so much the content of the language that is important here, but how patients operate with their affects, how they verbalize them and how aware they are of the subjective mental states. This leads to the understanding that a psychotherapeutic model designed for a specific clinical group of patients might focus on affect areas that are known to be problematic - in the case of borderline patients these are depressive and aggressive emotions, but also contempt towards others as we have showed. This model might be centered on consistent work in supporting the patient's ability to put words into emotions and to subjectivise them. This is how affects would not be experienced as something coming from the external environment and hence threatening and possibly traumatizing.

\section{Limitations of the Study}

The study has several important limitations. The number of participants is relatively small ( $\mathrm{n}=30$ in each group) which is due to the specific qualitative-quantitative methodology and the need for an exploratory study in a somehow new area. Second, the control group is parallel in sex, age and education, but the verbal and intellectual 
capabilities of the participants were not controlled, although they might affect the verbal elaboration of affect. Last but not least, the cross-sectional design doesn't allow followup of the patients and test-retest reliability of the assessment.

\section{Conclusion}

The present study is an attempt to deepen our understanding of the specifics of the psychic structure and mentalization capacities of heroin addicted patients. The results show significant impairments in all personality domains which leads to a fragmented, unbalanced view of self and others, lower capacity for maintaining deep and fulfilling interpersonal relationship as well as strong tendencies towards aggressive and selfaggressive behavior. These impairments in personality organization are connected to a disturbed capacity of verbalization and symbolization of affectivity that leads to to impulsive behavior. The results could be interpreted as confirming that early traumatic experiences impair mentalization capacities and therefore lead to disturbances in the development of the self. It would be safe to conclude that a therapeutic program which relies exclusively on medical and social aspects of rehabilitation, but doesn't takes into consideration personality organization specifics, would have only limited and temporary efficacy, since it doesn't address core deficits in that clinical group. A comprehensive treatment program should be focused on supporting the capacity to mentalize in areas that are clinically and empirically shown to be disturbed, especially in the hostile spectrum. Last, but not least, this study demonstrates the psychodiagnostic potential of language analysis - a time consuming methodology which might, however, bring results as valid or even better than standard self-report or structured measures. This approach might be used in assessment of structural changes due to psychotherapeutic work, as well as comparison of clinical groups sharing core deficits in mentalization abilities (e.g. patients with psychosomatic pathology or eating disorders).

\section{Acknowledgment}

This paper was supported by a grant from the International Psychoanalytical Association from the $6^{\text {th }}$ of March 2012.

\section{Biographical Note}

Nikola Atanassov, $\mathrm{PhD}$, is an associate professor of Clinical Psychology, Department of Cognitive Science and Psychology, New Bulgarian University in Sofia, Bulgaria. He is training analyst of the Bulgarian Psychoanalytic Society - a study group of the International Psychoanalytic Association - and teaches psychoanalytic theory to students of clinical psychology. He regards psychoanalysis as one of the major research tools of psychology and is interested in the points of contact between metapsychology and general psychology.

Svetoslav Savov, $\mathrm{PhD}$, is a clinical psychologist and assistant professor in the Department of Cognitive Science and Psychology, New Bulgarian University. He is an associate member and candidate of the Bulgarian Psychoanalytic Society, currently in private practice with children, adolescents and adults. 


\section{References}

Abraham, K. (1926). The psychological relations between sexuality and alcoholism. International Journal of Psycho-Analysis, 7, 2-10.

Allen J. G., Fonagy P., \& Bateman A. W. (2008). Mentalizing in clinical practice. Washington, DC: American Psychiatric Publishing.

Bateman, A. W. \& Fonagy, P. (2004). Psychotherapy for borderline personality disorder. Mentalization based treatment. New York, NY: Oxford University Press.

Bouchard, M.-A. \& Lecours, S. (2008). Contemporary approaches to mentalization in the light of Freud's project. In Busch, F (Ed.) Mentalization: theoretical considerations, research findings, and clinical implications (pp. 103-129). New York, NY: Taylor \& Francis Group.

Bouchard, M.-A., Target, M., Lecours, S., Fonagy, P., Tremblay, L.-M., \& Schachter, A. (2008). Mentalization in adult attachment narratives: reflective functioning, mental states, and affect elaboration compared. Psychoanalytic Psychology, 25, 4766.

Bucci, W., Kabasakalian, R. et al. (1992). Instructions for scoring referential activity (RA) in transcripts of spoken narrative texts. Ulm, Germany: Ulmer Textbank

Clarkin, J., Caligor, E., Stern, B., \& Kernberg, O. (2006). Structured interview of personality organization. New York, NY: Weill Medical College of Cornell University: Personality Disorders Institute.

de Mijolla, A. (Ed.) (2005). International dictionary of psychoanalysis. Farmington Hills, MI: Thomson Gale.

Doering, S., Burgmer, M., Heuft, G, Menke, D., Bäumer, B., Lübking, M., Feldman, M., Hörz, S. \& Schneider, G. (2013). Reliability and validity of the German version of the Structured Interview of Personality Organization (STIPO). BMC Psychiatry, 13, 210 .

Fenichel, O. (1945). The psychoanalytic theory of neurosis. New York, NY: W.W. Norton.

Fischer-Kern, M., Buchheim, A., Hörz, S., Schuster, P., Doering, S., Kapusta, N., Taubner, S., Tmej, A., Rentrop, M., Buchheim, P., \& Fonagy, P. (2010). The relationship between personality organization, reflective functioning, and psychiatric classification in borderline personality disorder. Psychoanalytic Psychology, 4, 395-409.

Fonagy, P. (2008). The mentalization-focused approach to social development. In Busch, F. (Ed.), Mentalization: theoretical considerations, research findings, and clinical implications (pp. 53-99). New York, NY: Taylor \& Francis Group.

Garland, C. (Ed.) (1998). Understanding trauma: a psychoanalytical approach. London, UK: Duckworth.

Glover, E. (1932). On the aetiology of drug-addiction. International Journal of PsychoAnalysis, 13, 298-328.

Gottschalk, L. A., \& Auerbach, A. (Eds.) (1966). Methods of research in psychotherapy. New York, NY: Appleton-Century-Crofts.

Hörz, S., Clarkin, J. F., Stern, B. L., \& Caligor, E. (2011). The Structured Interview of Personality Organization (STIPO): An Instrument to Assess Severity and Change of Personality Pathology. In R. A. Levy, J. S. Ablon, \& H. Kächele (Eds.), Psychodynamic psychotherapy research. evidence-based practice and practicebased evidence (pp. 571-592). New York, NY: Springer. 
Johansen, A. B., Darnell F. J., \& Franzen, E. (2013). Constructing a theory and evidencebased approach to promote and evaluate autonomy in addiction. Inquiry: an interdisciplinary journal in philosophy, 56, 539-557.

Jurist, E. L. (2005). Mentalized affectivity. Psychoanalytic Psychology, 22, 426-444.

Khantzian, E. (1980). Drug use as a protective system. In Lettieri, D., Sayers, M., \& Pearson, H. W. (Ed.), Theories on drug abuse: selected contemporary perspectives (pp. 71-75). Rockville, MD: National Institute on Drug Abuse.

Khantzian, E. J. (2003). Understanding addictive vulnerability: an evolving psychodynamic perspective. Neuro-Psychoanalysis, 5, 5-21.

Kernberg, O. (1975). Borderline conditions and pathological narcissism, New York, NY: Jason Aronson.

Kernberg, O. (2003). The management of affect storms in the psychoanalytic psychotherapy of borderline patients. Journal of the American Psychoanalytic Association, 51, 517-455.

Krystal, H. (1974). The genetic development of affects and affect regression. Annual of Psychoanalysis, 2, 98-126.

Krystal, H. (1975). Affect tolerance. Annual of Psychoanalysis, 3, 179-219.

Lecours, S. (2002). Manuel d'identification des contenus affectifs (MAC). Unpublished manuscript.

Laffal, J. (1965). Pathological and normal language. New York, NY: Atherton Press

Lecours, S. (2013). Verbal elaboration of affect scale scoring manual (version 7). Unpublished manuscript.

Lecours, S. \& Bouchard, M (1997). Dimensions of mentalization: outlining levels of psychic transformation. International Journal of Psychoanalysis, 78, 855-875.

Lecours, S., Bouchard, M.A., St-Amand, P., \& Perry, J. C. (2000). Assessing verbal elaboration of affect in psychotherapy: A preliminary report and single case study. Psychotherapy Research, 10, 47-56.

Lecours, S. \& Bouchard, M. (2011). Verbal elaboration of distinct affect categories and BPD Symptoms. Psychology and Psychotherapy: Theory, Research and Practice, 84, 26-41.

Lecours, S., Sanlian, N., \& Bouchard, M.-A. (2007). Assessing verbal elaboration of affect in clinical interviews: Exploring sex differences. Bulletin of the Menninger Clinic, 71, 227247.

Luborsky, L., \& Spence, D. P. (1971). Quantitative research on psychoanalytic therapy. In A. Bergin, \& S. Garfield, S. (Eds.), Handbook of psychotherapy and behavior change (pp. 408-438). New York, NY: John Wiley and Sons.

Piaget, J., \& Cook, M. T. (1952). The origins of intelligence in children. New York, NY: International University Press.

Marty, P. (1991). Mentalisation et psychosomatique. Paris, France: SynthélaboPiaget

Radó, S. (1928). The psychical effects of intoxication: attempt at a psychoanalyticaltheory of drug addiction. International Journal of Psycho-Analysis, 9 , 301-317.

Rentrop, M., Zilker, T., Lederle, A., Birkhofer, A., Hörz, S. (2014). Psychiatric comorbidity and personality structure in patients with polyvalent addiction. Psychopathology, 47, 133-140

Sifneos, P.E. (1973). The prevalence of alexithymic characteristics in psychosomatic patients. Psychotherapy and Psychosomatics, 22(2), 270-285.

Shedler, J., Mayman, M. \& Manis, M. (1993). 'The Illusion of Mental Health'. American Psychologist. 48, 1117-1131 
Stern, B., Caligor, E., Clarkin, J., Critchfield, K. L., Horz, S., MacCornack, V., Lenzenweger, M., \& Kernberg, O. (2010). structured interview of personality organization (STIPO): Preliminary psychometrics in a clinical sample. Journal of Personality Assessment, 92, 35-44

Taylor, G., Bagby, R., Parker, J. (1997). The development and regulation of affects. In G. Taylor, R. Bagby, \& J. Parker (Eds.), Disorders of affect regulation: alexithymia in medical and psychiatric illness (pp. 7-25). Cambridge, UK: Cambridge University Press.

Trull T. J., Sher, K.J., Minks-Brown, C., Durbin, J., \& Burr, R. (2000). Borderline personality disorder and substance use disorders: a review and integration. Clinical Psychology Review, 20, 235-253.

Walter, M., Berth, H., Selinger, J., Gerhard, U., Küchenhoff, J., Frommer, J., \& Dammann, G. (2009). The lack of negative affects as an indicator for identity disturbance in borderline personality disorder: A preliminary report. Psychopathology, 42, 399-404

Weinberg, E. (2006). Mentalization, affect regulation, and development of the self. Journal of the American Psychoanalytic Association, 54, 251-269.

Wieder, H. \& Kaplan, E. H. (1969). Drug use in adolescents - psychodynamic meaning and pharmacogenic effect. Psychoanalytic Study of the Child, 24, 399-431.

Woody, G. E. (1977). Psychiatric aspects of opiate dependence: diagnostic and therapeutic research issues. In Blaine, J. \& Julius, D. (Eds.) Psychodynamics of drug dependence (pp. 157-178). Rockville, MD: National Institute on Drug Abuse.

Wurmser, L. (1977). Mr. Pecksniff's horse? (Psychodynamics in compulsive drug use). In Blaine, J. \& Julius, D. (Eds.), Psychodynamics of drug dependence (pp. 36-72). Rockville, MD: National Institute on Drug Abuse. 